\title{
Convenient Way of Extend Linear Expenditure System Modeling without Regression
}

\author{
Ningning Song, Yiqing Liu \\ Hubei Normal University, Huangshi, China \\ Email: snn19880229@126.com
}

Received 5 April 2015; accepted 14 October 2015; published 20 October 2015

Copyright (C) 2015 by authors and Scientific Research Publishing Inc.

This work is licensed under the Creative Commons Attribution International License (CC BY). http://creativecommons.org/licenses/by/4.0/

\begin{abstract}
Extend Linear Expenditure System model is a collection of multiple linear models, and modeling is a clearly tedious process. The innovation of this paper is trying to find a simple way of ELES modeling, which means, in order to omit the modeling process one by one, we try to use Excel functionality to create a model workplace. As long as you replace the original sample data in the workspace, you can get the results you want.
\end{abstract}

Keywords

ELES Model, OLS, WLS

\section{Introduction}

ELES model is based on the assumption that people's demand for various goods or services in a certain period is determined by people's incomes and prices of various commodities, and the needs of people for a variety of goods are divided into two parts: people's basic needs and additional requirements exceeding the basic needs. At the same time, the model assumes that people's basic needs are irrelevant to the level of income, and people will allocate the residual income in accordance with the marginal propensity to consume to additional demands after people's basic needs are met. However, it is mainly used to calculate the marginal propensity to consume, basic consumption, income elasticity and price elasticity, which are reference quantities to study on structure change.

There are structure researches on ELES model in paper [1]-[4]. They are the perfect application. Paper [5] brings the ELES into demand research. Paper [6] [7] are the early studies in ELES. For a long time, ELES has laid a foundation for the quantitative study of the economy. However, its wide application and simple principle are liked by scholars, though they do not give a simple algorithm. We can find that authors use traditional, cumbersome and conservative method to calculate the results. In order to better apply ELES to scientific research, 
we want to simplify the process.

ELES model is a collection of multiple linear models, and in the case of many types of data, ELES modeling is a clearly tedious process and huge workload. If you need to test it, the equations are as much as stars in the sky, the quantity will make you mad. The innovation of this paper is trying to make the modeling method more simple, which means, in order to omit the modeling process one by one, we try to use Excel functionality to create a model workplace. As long as you replace the original sample data in the workspace, you can get the results you want.

\section{Formulas from ELES Model Derivation}

The basic expression of extended linear expenditure system (the abbreviation is ELES) is $C_{i}=p_{i} Q_{i}=p_{i} q_{i}^{0}+\beta_{i}\left(I-\sum_{i=1}^{n} p_{i} q_{i}^{0}\right), i=1,2, \cdots, n$, where $C_{i}$ is consumers' consumer spending on commodity or service $i, Q_{i}$ is consumers' demand for commodity or service $i, I$ is consumers' income, $\beta_{i}$ is the marginal propensity to consume of commodity or service $i, p_{i}$ is the price of commodity or service $i$, $q_{i}$ is basic demand for commodity or service $i, p_{i} q_{i}^{0}$ is basic expenditure for purchasing commodity or service $i$. Its economic significance is that people's demand for certain goods or services is divided into two parts: basic requirements and additional requirements. In the case of income and prices unchanged, people will allocate the residual income in accordance with the marginal propensity to consume to other all kinds of consumption of goods or services included in additional demands after people’s basic needs are met.

Transform the basic expression to get $C_{i}=\beta_{i} I+p_{i} q_{i}^{0}-\beta_{i} \sum_{i=1}^{n} p_{i} q_{i}^{0}$,

assume $\alpha_{i}=p_{i} q_{i}^{0}-\beta_{i} \sum_{i=1}^{n} p_{i} q_{i}^{0} \quad(1)$,

then, $C_{i}=\beta_{i} I+\alpha_{i}$.

Correspondingly, the econometric model is $C_{i}=\beta_{i} I+\alpha_{i}+u_{i}$.

Therefore, the sample data of consumption and income can be used to estimate model's parameters.

At the same time, via summation on either side of the equal sign of formula (1), calculation formula of total expenditure on basic consumption can be obtained as $C_{0}=\sum_{i=1}^{n} p_{i} q_{i}^{0}=\frac{\sum_{i=1}^{n} \alpha_{i}}{1-\sum_{i=1}^{n} \beta_{i}}$ (2), then, put it into formula (1) to get $p_{i} q_{i}^{0}=\left|\alpha_{i}+\beta_{i} \frac{\sum_{i=1}^{n} \alpha_{i}}{1-\sum_{i=1}^{n} \beta_{i}}\right|$ (3), which is used to figure out the basic expenditure for each commodity or service. In addition, you can also derive the income elasticity of commodity or service $i \quad \eta_{i}=\frac{\frac{\partial Q_{i}}{Q_{i}}}{\frac{\partial I}{I}}=\beta_{i} \frac{I}{C_{i}}$ (4); the cross price elasticity of commodity or service $i \quad \varepsilon_{i j}=\frac{\frac{\partial Q_{i}}{Q_{i}}}{\frac{\partial p_{j}}{p_{j}}}=-\beta_{i} \frac{p_{j} q_{j}}{C_{i}}$ (5); the own-price elasticity of commodity or service $i \quad \varepsilon_{i i}=\frac{\frac{\partial Q_{i}}{Q_{i}}}{\frac{\partial p_{i}}{p_{i}}}=-\beta_{i} \frac{\left(I-C_{0}+p_{i} q_{i}\right)}{C_{i}}$ 


\section{Ordinary Least Squares Estimate in Parameter Estimation of ELES}

Suppose residents from $n$ different income levels have m consumer items. Sample is used to estimate parameters of $m$ regression equations by ordinary least squares estimate (its abbreviations is OLS), process is as follows:

Assume one of the $m$ equations is $C_{i}=\hat{\beta}_{i} I_{i}+\hat{\alpha}_{i}+\hat{u}_{i}$,

its residual sum is $\sum \hat{u}_{i}^{2}=\sum\left(C_{i}-\hat{C}_{i}\right)^{2}=\sum\left(C_{i}-\hat{\beta}_{i} I_{i}-\hat{\alpha}_{i}\right)^{2}$,

According to the principle of OLS, equations are

$$
\begin{aligned}
& \frac{\partial \sum \hat{u}_{i}^{2}}{\partial \hat{\beta}_{i}}=-2 \sum\left(C_{i}-\hat{\beta}_{i} I_{i}-\hat{\alpha}_{i}\right)=0 \\
& \frac{\partial \sum \hat{u}_{i}^{2}}{\partial \hat{\alpha}_{i}}=-2 \sum\left(C_{i}-\hat{\beta}_{i} I_{i}-\hat{\alpha}_{i}\right) I_{i}=0
\end{aligned}
$$

Transform them into $\begin{aligned} & \sum C_{i}=n \hat{\alpha}_{i}+\hat{\beta}_{i} \sum I_{i} \\ & \sum C_{i} I_{i}=\hat{\alpha}_{i} \sum I_{i}+\hat{\beta}_{i} \sum I_{i}^{2},\end{aligned}$

then,

$$
\hat{\beta}_{i}=\frac{n \sum C_{i} I_{i}-\sum I_{i} \sum C_{i}}{n \sum I_{i}^{2}-\left(\sum I_{i}\right)^{2}}=\frac{\sum\left(I_{i}-\bar{I}\right)\left(C_{i}-\bar{C}\right)}{\sum\left(I_{i}-\bar{I}\right)^{2}}=\frac{S_{C I}-n \bar{I} C_{i}}{S_{I I}-n \bar{I}^{2}} \text {. }
$$

$$
\hat{\alpha}_{i}=\frac{\sum C_{i}-\hat{\beta}_{i} \sum I_{i}}{n}=\bar{C}_{i}-\hat{\beta}_{i} \bar{I}
$$

\section{Establish Workspace in Excel}

In this section, data of the annual per capita consumption expenditure of urban households in 2011, divided into $n$ levels on the basis of their income, is selected as samples to illustrate the established ELES model workspace in Excel, steps as follows:

1) Excel book is divided into four workspaces, original data area (A1:J10), the preparation area for calculation (B11:J20), ElES workspace (A21:J23) and elasticity zone (A24:J33).

2) Income group labels are established in the A1:A10, each consumption item label is established in the $\mathrm{B} 2: \mathrm{J} 10$, input sample data in the B2:J10, wherein, data in B10:J10 is the average level of consumption expenditures of urban residents and from NBS (National Bureau of Statistics of China).

3) Input averaging formula AVERAGE (B2:B9) in B11 to figure out the average of B2:B9, and copy the formula into C11:J11.

4) Input the formula $\mathrm{B} 2 * \mathrm{~B} 2$ in B12, and copy the formula into the rectangular region B12:J20.

5) Input the formula $\left(\mathrm{C} 20-8 * \mathrm{~B} 11^{*} \mathrm{C} 11\right) /(\mathrm{B} 20-8 * \mathrm{~B} 11 \wedge 2)$ in $\mathrm{C} 22$, and copy the formula into D22:J22. The formula calculates the slope of ELES model, which is the marginal propensity to consume.

6) Input the formula C11 - C22*B11 in C21, and copy the formula into D21:J21.

7) Input the formula $\mathrm{C} 21+\mathrm{C} 22 * \mathrm{~B} 25$ in $\mathrm{C} 23$, and copy the formula into D23:J23, also, it calculates the basic expenditure for purchasing each commodity or service.

8) Input the formula C22*B10/C10 in C24, and copy the formula into D24:J24, also, it calculates the income elasticity of each commodity or service.

9) Input the formula SUM(C21:J21)/(1 - SUM(C22:J22)) in C25, which calculates total basic expenditure of urban households.

10) Input the formula-D22*C23/D10 in C27, and copy the formula into the rectangular region C26:J33. What is more, the formula calculates the cross price elasticity of every commodity or service.

11) Input the formula-C22*(C23 + B10 - B25)/C10 in C26, and copy the formula into cells D27, E28, F29. G30, H31, I32, J33. As well as, the formula calculates the own price elasticity of every commodity or service.

Therefore, Table 1 was obtained.

\section{Illustration and Verification}

Replace the sample data in Original data area with data of the annual per capita consumption expenditure of urban households in 2012, to verify the above workspace in excel. The results are in Table 2. On the other hand, 
Table 1. Dynamic ELES modeling workspace in Excel.

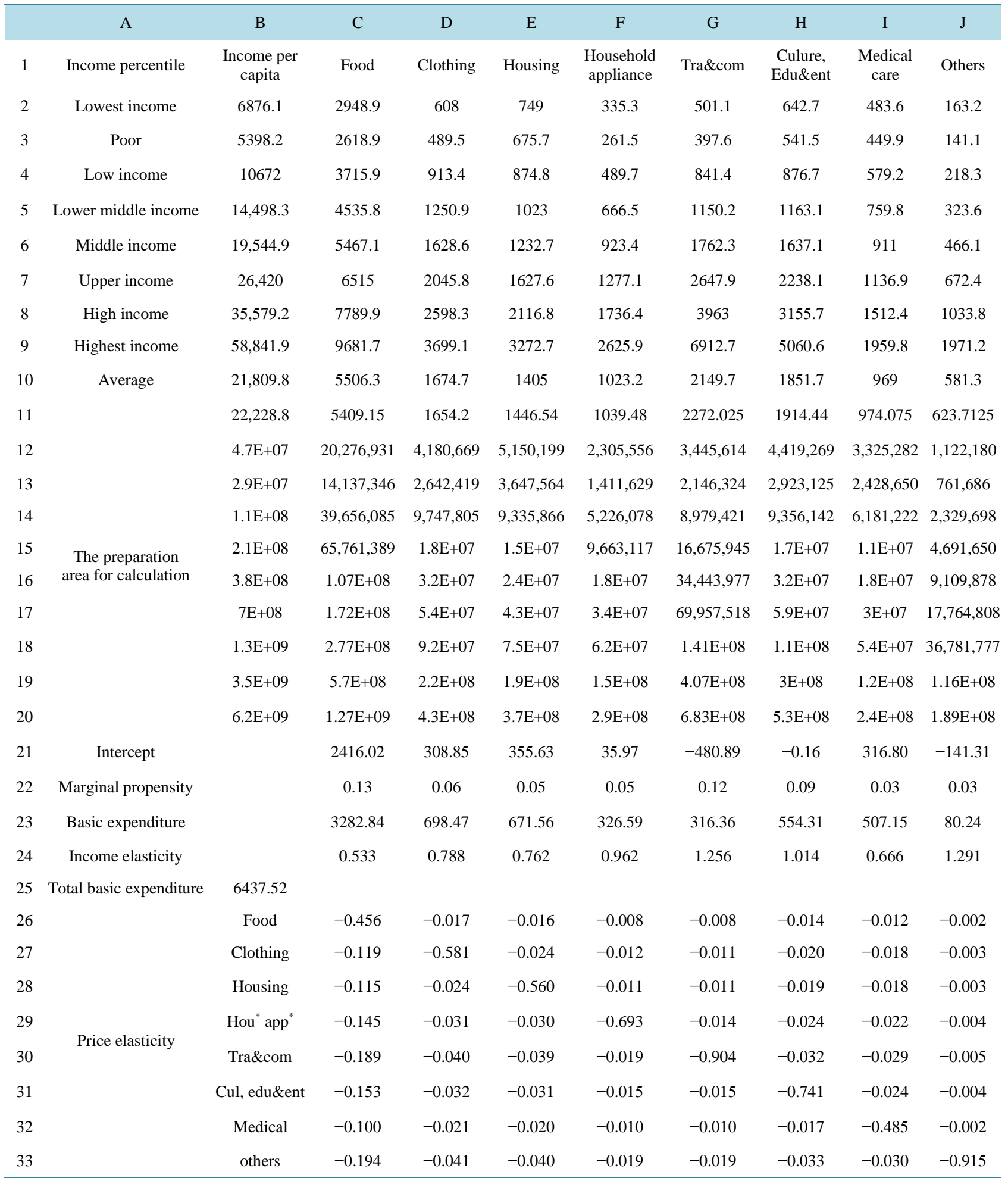

we use eview 5.0 software to regress the equations, whose results are in Table 3, to verify the workplace in excel.

Therefore, comparing Table 2 and Table 3, its results can be found as follows: the obtained values of marginal propensity to consume are the same, pass t test, and data doesn't have heteroscedasticity. 
Table 2. Dynamic ELES modeling workspace of data in 2012 in Excel.

\begin{tabular}{|c|c|c|c|c|c|c|c|c|c|c|}
\hline & A & B & $\mathrm{C}$ & $\mathrm{D}$ & E & $\mathrm{F}$ & G & $\mathrm{H}$ & I & $\mathrm{J}$ \\
\hline 1 & Income percentile & $\begin{array}{l}\text { Income per } \\
\text { capita }\end{array}$ & Food & Clothing & Housing & $\begin{array}{l}\text { Household } \\
\text { appliance }\end{array}$ & Tra\&com & $\begin{array}{l}\text { Culure, } \\
\text { edu\&ent }\end{array}$ & $\begin{array}{l}\text { Medical } \\
\text { care }\end{array}$ & Others \\
\hline 2 & Lowest income & 8215.1 & 3310.4 & 706.8 & 832.6 & 405.4 & 602.8 & 723 & 548.3 & 172.1 \\
\hline 3 & Poor & 6520 & 2979.3 & 589.8 & 759.6 & 333.1 & 495.3 & 613.9 & 466.5 & 129.2 \\
\hline 4 & Low income & $12,488.6$ & 4147.4 & 1045.5 & 924.5 & 569.3 & 954.4 & 1034.9 & 669.6 & 265 \\
\hline 5 & Lower middle income & $16,761.4$ & 5028.6 & 1408.2 & 1160.4 & 760 & 1393 & 1326.6 & 832.9 & 371.1 \\
\hline 6 & Middle income & 22,419.1 & 6061.4 & 1765.9 & 1384.3 & 1033.6 & 2063.3 & 1785.5 & 1096 & 529.9 \\
\hline 7 & Upper income & $29,813.7$ & 7102.4 & 2213.8 & 1708.7 & 1346.2 & 2960.6 & 2449.1 & 1248.9 & 800.4 \\
\hline 8 & High income & $39,605.2$ & 8561 & 2767.5 & 2154.3 & 1827.9 & 4304.1 & 3432.8 & 1580 & 1169.4 \\
\hline 9 & Highest income & $63,824.2$ & $10,323.1$ & 3928.5 & 3123.3 & 2807.3 & 7971.1 & 5431.6 & 1951.1 & 2125.7 \\
\hline 10 & Average & $24,564.7$ & 6040.9 & 1823.4 & 1484.3 & 1116.1 & 2455.5 & 2033.5 & 1063.7 & 657.1 \\
\hline 11 & & $24,955.9$ & 5939.2 & 1803.25 & 1505.96 & 1135.35 & 2593.075 & 2099.68 & 1049.16 & 695.35 \\
\hline 12 & & $6.7 \mathrm{E}+07$ & $27,195,267$ & $5,806,433$ & $6,839,892$ & $3,330,402$ & 4,952,062 & $5,939,517$ & $4,504,339$ & $1,413,819$ \\
\hline 13 & & $4.3 \mathrm{E}+07$ & $19,425,036$ & $3,845,496$ & 4,952,592 & $2,171,812$ & $3,229,356$ & $4,002,628$ & $3,041,580$ & 842,384 \\
\hline 14 & & $1.6 \mathrm{E}+08$ & $51,795,220$ & $1.3 \mathrm{E}+07$ & $1.2 \mathrm{E}+07$ & $7,109,760$ & $11,919,120$ & $1.3 \mathrm{E}+07$ & $8,362,367$ & $3,309,479$ \\
\hline 15 & The preparation & $2.8 \mathrm{E}+08$ & $84,286,376$ & $2.4 \mathrm{E}+07$ & $1.9 \mathrm{E}+07$ & $1.3 \mathrm{E}+07$ & 23,348,630 & $2.2 \mathrm{E}+07$ & $1.4 \mathrm{E}+07$ & 6,220,156 \\
\hline 16 & area for calculation & $5 \mathrm{E}+08$ & $1.36 \mathrm{E}+08$ & $4 \mathrm{E}+07$ & $3.1 \mathrm{E}+07$ & $2.3 \mathrm{E}+07$ & $46,257,329$ & $4 \mathrm{E}+07$ & $2.5 \mathrm{E}+07$ & $11,879,881$ \\
\hline 17 & & $8.9 E+08$ & $2.12 \mathrm{E}+08$ & $6.6 \mathrm{E}+07$ & $5.1 \mathrm{E}+07$ & $4 \mathrm{E}+07$ & $88,266,440$ & $7.3 \mathrm{E}+07$ & $3.7 \mathrm{E}+07$ & $23,862,885$ \\
\hline 18 & & $1.6 \mathrm{E}+09$ & $3.39 \mathrm{E}+08$ & $1.1 \mathrm{E}+08$ & $8.5 \mathrm{E}+07$ & $7.2 \mathrm{E}+07$ & $1.7 \mathrm{E}+08$ & $1.4 \mathrm{E}+08$ & $6.3 \mathrm{E}+07$ & $46,314,321$ \\
\hline 19 & & $4.1 \mathrm{E}+09$ & $6.59 \mathrm{E}+08$ & $2.5 \mathrm{E}+08$ & $2 \mathrm{E}+08$ & $1.8 \mathrm{E}+08$ & $5.09 \mathrm{E}+08$ & $3.5 E+08$ & $1.2 \mathrm{E}+08$ & $1.36 \mathrm{E}+08$ \\
\hline 20 & & $7.6 \mathrm{E}+09$ & $1.53 \mathrm{E}+09$ & $5.1 \mathrm{E}+08$ & $4.1 \mathrm{E}+08$ & $3.4 \mathrm{E}+08$ & $8.57 \mathrm{E}+08$ & $6.4 \mathrm{E}+08$ & $2.8 \mathrm{E}+08$ & $2.3 \mathrm{E}+08$ \\
\hline 21 & Intercept & & 2649.14 & 341.01 & 461.20 & 44.59 & -667.84 & -28.68 & 383.35 & -175.76 \\
\hline 22 & Marginal propensity & & 0.13 & 0.06 & 0.04 & 0.04 & 0.13 & 0.09 & 0.03 & 0.03 \\
\hline 23 & Basic expenditure & & 3537.07 & 735.64 & 743.16 & 338.97 & 212.22 & 545.73 & 563.04 & 59.34 \\
\hline 24 & Income elasticity & & 0.536 & 0.789 & 0.693 & 0.962 & 1.307 & 1.030 & 0.616 & 1.305 \\
\hline 25 & Total basic expenditure & 6735.17 & & & & & & & & \\
\hline 26 & & Food & -0.466 & -0.016 & -0.016 & -0.007 & -0.005 & -0.012 & -0.012 & -0.001 \\
\hline 27 & & Clothing & -0.114 & -0.597 & -0.024 & -0.011 & -0.007 & -0.018 & -0.018 & -0.002 \\
\hline 28 & & Housing & -0.100 & -0.021 & -0.524 & -0.010 & -0.006 & -0.015 & -0.016 & -0.002 \\
\hline 29 & Price elasticit & Hou* app $^{*}$ & -0.139 & -0.029 & -0.029 & -0.711 & -0.008 & -0.021 & -0.022 & -0.002 \\
\hline 30 & Fince eidsticity & Tra\&com & -0.188 & -0.039 & -0.040 & -0.018 & -0.960 & -0.029 & -0.030 & -0.003 \\
\hline 31 & & Cul, edu\&ent & -0.148 & -0.031 & -0.031 & -0.014 & -0.009 & -0.771 & -0.024 & -0.002 \\
\hline 32 & & Medical & -0.089 & -0.018 & -0.019 & -0.009 & -0.005 & -0.014 & -0.461 & -0.001 \\
\hline 33 & & Others & -0.188 & -0.039 & -0.039 & -0.018 & -0.011 & -0.029 & -0.030 & -0.950 \\
\hline
\end{tabular}

Table 3. Results of the regression with eview 5.0 software.

\begin{tabular}{|c|c|c|c|c|c|c|c|c|}
\hline & $\mathrm{C} 1$ & $\mathrm{C} 2$ & C3 & $\mathrm{C} 4$ & C5 & C6 & C7 & C8 \\
\hline Intercept & 2666.681 & 345.9387 & 460.5944 & 44.34132 & -677.737 & -32.43652 & 386.2129 & -178.5756 \\
\hline Slope & 0.131814 & 0.058587 & 0.041865 & 0.043708 & 0.130679 & 0.085289 & 0.026676 & 0.034909 \\
\hline t-Statistic & 12.45697 & 24.57792 & 69.801650 & 89.87068 & 27.84007 & 59.28272 & 13.61498 & 27.82504 \\
\hline P-t & 0.0000 & 0.0000 & 0.0000 & 0.0000 & 0.0000 & 0.0000 & 0.0000 & 0.0000 \\
\hline p-white & 0.060171 & 0.098096 & 0.62869 & 0.280624 & 0.293578 & 0.584147 & 0.096307 & 0.283249 \\
\hline
\end{tabular}




\section{Weighted Least Squares Estimate in Parameter Estimation of ELES}

In the above discussion, perhaps the selected data happens to have just no heteroscedasticity. However, if there is heteroscedasticity data, weighted least squares estimate (its abbreviation is WLS) will be used to estimate the parameters, whose principle is adding a weight in front of residuals, and the derivation process is as follows:

Its residual sum is $\sum \hat{u}_{i}^{2}=\sum W_{i}\left(C_{i}-\hat{C}_{i}\right)^{2}=\sum W_{i}\left(C_{i}-\hat{\beta}_{i} I_{i}-\hat{\alpha}_{i}\right)^{2}$,

according to the principle of WLS, equations are

$$
\begin{aligned}
& \frac{\partial \sum \hat{u}_{i}^{2}}{\partial \hat{\beta}_{i}}=-2 \sum W_{i}\left(C_{i}-\hat{\beta}_{i} I_{i}-\hat{\alpha}_{i}\right)=0 \\
& \frac{\partial \sum \hat{u}_{i}^{2}}{\partial \hat{\alpha}_{i}}=-2 \sum W_{i}\left(C_{i}-\hat{\beta}_{i} I_{i}-\hat{\alpha}_{i}\right) I_{i}=0
\end{aligned},
$$

and transform them into $\sum W_{i} C_{i}=\hat{\alpha}_{i} \sum W_{i}+\hat{\beta}_{i} \sum W_{i} I_{i}$

$$
\sum W_{i} C_{i} I_{i}=\hat{\alpha}_{i} \sum W_{i} I_{i}+\hat{\beta}_{i} \sum W_{i} I_{i}^{2}
$$

$$
\begin{aligned}
\hat{\beta}_{i}= & \frac{\sum W_{i} C_{i} I_{i}-\frac{\sum W_{i} I_{i} \sum W_{i} C_{i}}{\sum W_{i}}}{\sum W_{i} I_{i}^{2}-\frac{\left(\sum W_{i} I_{i}\right)^{2}}{\sum W_{i}}} \\
\text { then, } \quad & \hat{\alpha}_{i}=\frac{\sum W_{i} C_{i}}{\sum W_{i}}-\frac{\sum W_{i} \sum W_{i} C_{i} I_{i} \sum W_{i} I_{i}-\sum W_{i} I_{i} \sum W_{i} C_{i}}{\left(\sum W_{i}\right)^{2} \sum W_{i} I_{i}^{2}-\left(\sum W_{i} I_{i}\right)^{2} \sum W_{i}}
\end{aligned}
$$

In the process of the establishment, put the $W_{i}$ that you defined in front of the formulas into the cell. $W_{i}$ can also be $\hat{\sigma}, \hat{\sigma}^{2}, \hat{S}^{2}, \hat{S}$ or any other. The different establishment process is just slightly modified the formula, other build steps are the same as OLS.

\section{References}

[1] Bian, S. (2014) Solution to the Problem of Urban Low Negative Incentive System of Employment-Based on "Senders" and "Negative Income Tax System". China Soft Science, 10, 51. (In Chinese)

[2] Han, Z.-C., Li, X.-X. and Li, Z.-X. (2011) Comparison among the Consumption Structures of Different Income Groups of Urban Residents in Guangxi Based on ELES Model. Asian Agricultural Research, 1, 11-13.

[3] Chen, L.-Y. and Li, W. (2009) Changes of Consumption Expenditure of Urban and Rural Residents in Ningxia, ChinaBased on the Expanded Linear Expenditure System Model. Asian Agricultural Research, 1, 16-19.

[4] Li, T.-T., Shi, C.-L. and Zhang, A.-L. (2011) Research on Consumption Structure of Rural Residents in Gansu Province Based on ELES Model. Asian Agricultural Research, 3, 34-37.

[5] Stone, R. (1954) Linear Expenditure Systems and Demand Analysis: An Application to the Pattern of British Demand. The Economic Journal, 64, 511-527. http://dx.doi.org/10.2307/2227743

[6] Lluch, C. (1973) The Extended Linear Expenditure System. European Economic Review, 4, 21-32.

[7] Phlips, L. (1972) A Dynamic Version of the Linear Expenditure Model. The Review of Economics and Statistics, 54, 450-458. http://dx.doi.org/10.2307/1924573 